\title{
命HAD
}

ISSN-L: 2530-5115

DOI: http://doi.org/10.22585/hospdomic.v4i2.105

\section{La Hospitalización a Domicilio en la enfermedad del COVID-19}

\author{
Home Hospitalization in COVID-19 disease
}

Carmina Wanden-Berghe', Javier Sanz-Valero²

1. Directora de la revista Hospital a Domicilio, Alicante, España.

2. Editor jefe de la revista Hospital a Domicilio, Alicante, España.

Correspondencia/Correspondence

Javier Sanz-Valero

editor@revistahad.eu

Recibido/Received

02.04.2020

Aceptado/Accepted

03.04.2020
Conflicto de Intereses/Competing interest

Los autores del trabajo declaran no tener ningún conflicto de interés.

Financiación

No se han recibido fuentes de financiación. 
El 31 de diciembre de 2019 las Autoridades de la República Popular China, comunicaron a la OMS varios casos de neumonía de etiología desconocida en Wuhan, una ciudad situada en la provincia china de Hubei. Una semana más tarde confirmaron que se trataba de un nuevo coronavirus que ha sido denominado SARS-CoV-2. El 30 de enero la Organización Mundial de la Salud declaró el brote de SARS-CoV-2 en China Emergencia de Salud Pública de Importancia Internacional (1).

Al igual que otros de la familia de los coronavirus, este virus causa diversas manifestaciones clínicas englobadas bajo el término COVID-19, que incluyen cuadros respiratorios que varían desde el resfriado común hasta cuadros de neumonía grave con síndrome de distrés respiratorio, shock séptico y fallo multi-orgánico. La mayoría de los casos de COVID-19 notificados hasta el momento debutan con cuadros leves (2).

Por el momento, no existe tratamiento específico, con lo que se realiza tratamiento sintomático en los casos leves y moderados, y medidas de soporte o tratamiento de complicaciones en casos graves (3).

Según el documento técnico del Ministerio de Sanidad del Gobierno de España «Manejo domiciliario del COVID-19», en el momento actual la atención domiciliaria es la opción preferente para la detección de casos posibles con síntomas leves, sin ninguna comorbilidad importante y situación clínica estable, siempre y cuando el entorno domiciliario sea adecuado para la atención sanitaria del caso y se cumplan unos requisitos mínimos (2).

En este documento, establece como los criterios para considerar la atención domiciliaria, los siguientes:

- Casos posibles, probables o confirmados de COVID-19 con síntomas leves1 y sin criterios de ingreso hospitalario (se valorará individualmente según la situación clínica y el momento epidemiológico concreto).

- Casos probables o confirmados de COVID-19 que han precisado hospitalización y que han recibido el alta hospitalaria, pero requieren seguimiento y medidas de aislamiento.

Asimismo, establece los requisitos para que pueda llevarse a cabo dicha atención domiciliaria:

- No es necesario que el paciente viva acompañado si se puede asegurar una asistencia telefónica.

- El paciente debe disponer de un teléfono que garantice la comunicación permanente con el personal sanitario hasta la resolución de los síntomas.

- Aunque cada caso se deberá valorar de forma individual, como norma general no debería haber convivientes con condiciones de salud que supongan una vulnerabilidad: edad avanzada, diversidad funcional, enfermedades crónicas, inmunodepresión, embarazo...

- Tanto el paciente como sus convivientes deben ser capaces de comprender y aplicar de forma correcta y consistente las medidas básicas de higiene, prevención y control de la infección.

- El centro sanitario contará con capacidad para realizar una atención y seguimiento domiciliarios, idealmente mediante controles por vía telefónica o presencial cuando se considere necesario.

Estos criterios y recomendaciones están en línea con las orientaciones que la Organización Mundial de la Salud publicó, de forma provisional, sobre cómo cuidar de los pacientes sospechosos de haber contraído el nuevo coronavirus que causa la COVID-19 y que presenten síntomas leves, así como sobre las medidas de salud pública relativas al manejo de sus contactos (4).

Así pues, en aquellos casos que se cumplen los criterios, nadie duda de que la Hospitalización a Domicilio $(\mathrm{HaD})$ aporta ventajas como alternativa a la hospitalización convencional, existiendo evidencia acerca de dichas ventajas en lo que respecta a la eficacia, seguridad y al alto nivel de 
satisfacción de esta modalidad asistencial. Los factores clave para su correcta implementación son garantizar una adecuada selección de los pacientes tributarios de HaD y disponer de un equipo experimentado en atención de casos complejos en el domicilio. Además, existe evidencia que corrobora que a los beneficios asistenciales hay que sumar un ahorro de costes respecto a la hospitalización convencional (5).

Conjuntamente, a las ventajas que aporta la $\mathrm{HaD}$, en poco tiempo, han aparecido un elevadísimo número de pacientes COVID-19 que sobrepasan la capacidad asistencial habitual de los centros hospitalarios, así como de los recursos proporcionados por Atención Primaria. En el contexto epidemiológico actual de la infección por COVID-19 en España con el progresivo aumento de los casos sintomáticos en las próximas semanas, la Sociedad Española de Hospitalización a Domicilio (SEHAD) se plantea como una opción en el manejo de estos pacientes. Y, ya son varias las comunidades autónomas que han implicado a la HAD en sus dispositivos de atención a pacientes con coronavirus o que han incluido a estas Unidades en los planes de contingencia de algunos de sus centros asistenciales.

En este contexto, la Sociedad Española de Hospitalización a Domicilio (SEHAD) publica en este número de la revista Hospital a Domicilio el protocolo sobre «Derivación a hospitalización a domicilio de pacientes con infección por COVID-19» (6).

\section{BIBLIOGRAFÍA}

1. Centro de Coordinación de Alertas y Emergencias Sanitarias. Valoración de la declaración del brote de nuevo coronavirus 2019 (n-CoV) una Emergencia de Salud Pública de Importancia Internacional (ESPII) [monografía en Internet]. Madrid, España: Dirección General de Salud Pública, Calidad e Innovación, Ministerio de Sanidad; 2020 [citado 1 de abril de 2020]. Disponible en: https://bit.ly/3aEpCvk

2. Centro de Coordinación de Alertas y Emergencias Sanitarias. Documento técnico: Manejo domiciliario del COVID-19 [monografía en Internet]. Madrid, España: Dirección General de Salud Pública, Calidad e Innovación, Ministerio de Sanidad; 2020 [citado 1 de abril de 2020]. Disponible en: https://bit.ly/3448Blv

3. Centro de Coordinación de Alertas y Emergencias Sanitarias. Documento técnico: Manejo pediátrico en atención primaria del COVID-19 [monografía en Internet]. Madrid, España: Dirección General de Salud Pública, Calidad e Innovación, Ministerio de Sanidad; 2020 [citado 1 de abril de 2020]. Disponible en: https://bit.ly/3448Blv

4. Organización Mundial de la Salud (OMS). Atención en el domicilio a pacientes presuntamente infectados por el nuevo coronavirus (COVID-19) que presentan síntomas leves y gestión de sus contactos [monografía en Internet]. Ginebra, Suiza: OMS; 2020 [citado 1 de abril de 2020]. Disponible en: https://bit.ly/3dLbceV

5. Estrada Cuxart O, Massa Domínguez B, Ponce González MÁ, Mirón Rubio M, Torres Corts A, Mujal Martínez A, et al. Proyecto HAD 2020: una propuesta para consolidar la hospitalización a domicilio en España. Hosp Domic. 2017;1(2):93-117. DOI: 10.22585/hospdomic.v1i2.13

6. Mujal Martínez A, Regalado de los Cobos J, Ruiz Castellano M, Mirón Rubio M, Basterretxea Ozamiz A, Estrada Cuxart O, et al. Derivación a hospitalización a domicilio de pacientes con infección por COVID-19. Hosp Domic. 2020;4(2):59-67. DOI: 10.22585/hospdomic.v4i2.104 